\title{
Dedicated multidisciplinary pain management centres for children in Canada: the current status
}

\author{
[Les centres pluridisciplinaires de prise en charge de la douleur consacrés aux \\ enfants au Canada : état actuel]
}

Philip Peng MD, ${ }^{*}$ Jennifer N. Stinson PhD, $†$ Manon Choiniere PhD, $\ddagger$ Dominique Dion MD MSc, $\mathfrak{S}$ Howard Intrater FRCPC, $\mathbb{I}$ Sandra LeFort PhD,\| Mary Lynch FrCPC, ${ }^{* *}$ May Ong FRCPC, †† Saifee Rashiq MSc (Epid) DA (UK) FRCPC,ł‡ Gregg Tkachuk PhD,\$S Yves Veillette FRCPC,III STOPPAIN Investigators Group

Purpose: The objective of this study was to examine the services currently offered by multidisciplinary pain treatment facilities (MPTFs) dedicated for pediatric chronic pain management across Canada.

Methods: A MPTF was defined as a clinic that advertised specialized multidisciplinary services for the diagnosis and management of chronic pain and had a minimum of three different health care disciplines (including at least one medical speciality) available and integrated within the facility. The search method was previously described in an accompanying article. Designated investigators were responsible for confirming and supplementing MPTFs from the preliminary list in their respective provinces. Administrative leads at each eligible MPTF were asked to complete a detailed questionnaire on their infrastructure, clinical, research, teaching and administrative activities. Only MPTFs dedicated to pediatric populations were included.

Results: Only five centres surveyed had dedicated pediatric MPTFs, all located in major cities in five different provinces. While the median wait time was four weeks, it could be as long as nine months in one MPTF. Headache and neuropathic pain were the most commonly treated pain syndromes. All MPTFs included physicians, nurses and psychologists, and used a rehabilitation model that incorporated a wide variety of pharmacological, psychological and physical therapies. All centres provided training for medical and other healthcare professionals, and three of the five centres conducted research. Government funding was the major source of funding for patient services and overhead costs.

Conclusions: There are very few pediatric MPTFs in Canada. These facilities exist in five of ten provinces, each within large urban centres. Limited accessibility leads to variable and prolonged wait times for pediatric patients suffering from chronic pain.

CAN J ANESTH $2007 / 54: 12 /$ pp 985-991

Objectif : L'objectif de cette étude était d'examiner les services actuellement offerts par les établissements pluridisciplinaires de traitement de la douleur (MPTF - multidisciplinary pain treatment facility) spécialisés dans la prise en charge des douleurs chroniques chez les enfants au Canada.

Méthode : Un MPTF a été défini comme une clinique affichant des services pluridisciplinaires spécialisés pour le diagnostic et la prise en charge des patients souffrant de douleurs chroniques, et possédant au moins trois disciplines différentes de soins de

From the Wasser Pain Management Centre, ${ }^{*}$ Mount Sinai Hospital, University of Toronto, Toronto, Ontario; the Faculty of Nursing, $\dagger$ University of Toronto, The Hospital for Sick Children, Toronto, Ontario; the Department of Anesthesia, $\ddagger$ Montreal Heart Institute, Faculty of Medicine, University of Montreal, Montreal, Quebec; the Department of Family Medicine, $\$$ Hôpital Maisonneuve-Rosemont, Faculty of Medicine, University of Montreal, Montreal, Quebec; the Health Science Centre Pain Clinic, I Winnipeg, Manitoba; the School of Nursing, || Memorial University, St. John's, Newfoundland; the Pain Management Unit, ** Queen Elizabeth II Health Centre, Halifax,

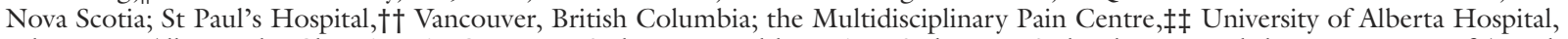
Edmonton, Alberta; the Chronic Pain Centre, II Saskatoon Health Region, Saskatoon, Saskatchewan; and the Department of Anesthesia, Clinique Anti-douleur, || Hôpital Maisonneuve-Rosemont, Faculty of Medicine, University of Montreal, Montreal, Quebec, Canada. Address correspondence to: Dr. Philip Peng, McL 2-405 Toronto Western Hospital, 399 Bathurst Street, Toronto, Ontario M5T 2S8, Canada. Phone: 416-603-5118; Fax: 416-603-6494; E-mail: philip.peng@uhn.on.ca Competing interest: None declared.

Funding: The study was funded by the Canadian Institutes of Health Research (via the CIHR/Rx\&D Collaborative Research Program) in partnership with Pfizer Canada and the three networks of the Fonds de la recherche en santé du Québec (Santé buccodentaire, Adaptionréadaption, Neurosciences et santé mentale).

Accepted for publication July 10, 2007.

Revision accepted September 3, 2007.

This article is accompanied by an editorial. Please see Can J Anesth 2007; 54: 963-8. 
santé (y compris au moins une spécialité médicale) à disposition et intégrées dans l'établissement. La méthode de recherche a été précédemment décrite dans un article concomitant. Des chercheurs désignés étaient responsables de la confirmation et de l'ajout de MPTF à la liste préliminaire dans leur province respective. On a demandé à la direction administrative de chaque MPTF éligible de remplir un questionnaire détaillé concernant l'infrastructure de son MPTF ainsi que ses activités de soins, de recherche, d'enseignement et de gestion. Seuls les MPTF se consacrant aux enfants ont été inclus.

Résultats : Seulement cinq des centres contactés offraient des MPTF pédiatriques spécialisés, tous situés dans des grandes villes de cinq provinces différentes. Bien que le temps d'attente médian soit de quatre semaines, il pouvait aller jusqu'à neuf mois dans un des établissements. Les maux de tête et les douleurs neuropathiques constituaient les syndromes de la douleur les plus fréquemment soignés. Tous les MPTF comptaient des médecins, des infirmiers, infirmières et psychologues, et utilisaient un modèle de réhabilitation qui comprenait une grande diversité de traitements pharmacologiques, psychologiques et physiques. Tous ces centres fournissent une formation pour les professionnels médicaux et de la santé, et il existait de la recherche dans trois des cinq établissements. Le financement public constituait la source la plus importante de financement pour les services aux patients et pour les frais généraux.

Conclusion: II n'existe que très peu d'établissements pluridisciplinaires de traitement de la douleur spécialisés en pédiatrie au Canada. Ces centres existent dans cinq des dix provinces, et tous se trouvent dans des centres urbains d'envergure. Un accès limité engendre des temps d'attente variables et prolongés pour les enfants souffrant de douleurs chroniques.

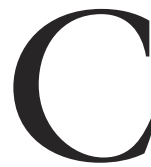

HILDREN experience a wide variety of recurrent and chronic pain entities. ${ }^{1-3} \mathrm{~A}$ recent epidemiological study in southwestern Ontario found that $57 \%$ of school age children reported having at least one recurrent pain (e.g., headaches, stomach pains and growing pains) and $6 \%$ were found to have chronic pain (e.g., illnessrelated pain, back pain). ${ }^{2}$ Chronic pain in children is defined as any recurring (e.g., headache, abdominal and limb pain) or persistent pain (e.g., back pain, cancer pain, complex regional pain syndrome) that lasts a minimum of three months. ${ }^{3}$ Chronic pain adversely affects all aspects of children's lives (physical, psychological and social functioning). ${ }^{4-7}$ Pain in children is now recognized as a major health problem because of its prevalence, ${ }^{1,2}$ negative impact on all aspects of quality of life, ${ }^{4-7}$ and economic burden. ${ }^{8}$
Given the negative impact of pain on physical and psychosocial functioning, specialized interdisciplinary chronic pain teams are now considered the standard of care for children and adults with chronic pain conditions. ${ }^{9,10, \mathrm{~A}, \mathrm{~B}}$ The need for multidisciplinary pain treatment programs has been acknowledged by professional organizations [e.g., International Association for the Study of Pain (IASP), Canadian Pain Society], , C $^{\mathrm{A}}$ quality care initiatives (e.g., development of clinical practice guidelines), ${ }^{\mathrm{D}}$ and health services accreditation bodies in Canada and the United States. ${ }^{\mathrm{E}, \mathrm{F}}$ While multidisciplinary treatment programs have been shown to be effective in adults with chronic pain, ${ }^{11-15, \mathrm{~A}}$ evidence for their effectiveness in children is sparse. ${ }^{16}$ More importantly, little is known about the multidisciplinary pain treatment facilities (MPTFs) services for the pediatric population in Canada. Therefore, the objective of this study was to determine the availability of dedicated pediatric multidisciplinary pain treatment facilities across Canada and describe the services that are currently offered by these programs. This was part of the STOPPAIN project in which all MPTFs for all age groups were surveyed. ${ }^{17}$

A IASP - International Association for the Study of Pain. Task Force on Guidelines for Desirable Characteristics for Pain Treatment Facilities, IASP. Desirable characteristics for pain treatment facilities. Available from URL; http://www.iasp-pain. org/desirabl.html (accessed August 18, 2007).

B Ospina M, Harstal C. Multidisciplinary Pain Programs for Chronic Pain: Evidence from systematic reviews. Alberta Heritage Foundation for Medical Research - Health Technology Assessment, Alberta, Canada, 2003: 1-48.

C Canadian Pain Society. Establishing Acceptable Waiting Times for Treatment of Pain in Canada. Available from URL; http:// www.canadianpainsociety.ca/WaitTimes_Report.pdf (accessed August 18, 2007)

D College of Physicians and Surgeons of Ontario. Evidence-based Recommendations for Medical Management of Chronic NonMalignant Pain: Reference Guide for Clinicians. Available from URL; http://www.cpso.on.ca/publications/pain.PDF (accessed August 18, 2007).

E Accreditation Pain Standard: Making it happen. Canadian Council on Health Services Accreditation. (2003). CCHSA and patient safety. Available from URL; http://www.cchsa-ccass. ca/default.aspx?page=235 (accessed August 18, 2007).

F The Joint Commission. Nutritional, functional, pain assessment and screens. Comprehensive Accreditation Manual for Hospital. Joint Commission on Accreditation of Healthcare Organizations. Available from URL; http://www.jointcommis sion.org/AccreditationPrograms/Hospitals/Standards/FAQs/ Provision+of+Care/Assessment/nfp_assessments.htm (accessed August 18, 2007) 


\section{Methods}

Definition of MPTFs

In the present study, a MPTF was defined as a health care delivery facility staffed with health care professionals who are specialized in the diagnosis and management of pediatric patients with chronic pain. To be included in the study, the MPTF had to l) advertise itself as a pain clinic or a pain centre and/or specialized multidisciplinary services for the diagnosis and management of patients with chronic non-malignant pain; and 2) be staffed with a minimum of three different health care disciplines (whose services were available and integrated within the pain clinic or centre) including at least one medical speciality. In addition, for this study, the MPTF had to provide services to children between the ages of birth to $18 \mathrm{yr}$ of age.

\section{Study procedures}

Because there was no pre-existing complete list of MPTFs in Canada, a comprehensive search strategy was used to identify all existing MPTFs. To identify hospital-based MPTFs, letters were sent to the medical directors and/or chief executive officer of all hospitals and rehabilitation centres across Canada, asking whether there was a pain clinic or a pain centre within their institution. The complete list of those hospitals or healthcare facilities was obtained from the Guide to Canadian Healthcare Facilities 2004-5 (Canadian Healthcare Association). Upon confirmation of presence of a pain clinic, representatives from each were asked to provide the name of the director and contact information of the clinic. Non-hospital based or private clinics were identified by contacting provincial compensation agencies (work or car accident), the Insurance Bureau of Canada, and pharmaceutical industry representatives. Following this process, a preliminary list was made available to the study representatives of each province (provincial representatives), who were pain clinicians or researchers with an excellent knowledge of the pain clinics and centres in their provinces. Each provincial representative contacted the pain clinics from the preliminary list to ensure their eligibility based on the definition of MPTF described above.

Following Ethics Review Board approval, the directors of the potential MPTFs were contacted by regular or electronic mail with an invitation to participate in this study. If they agreed to participate, they were sent the survey questionnaire. If the questionnaire was not received within three weeks after delivery, the director was sent a reminder by mail or contacted by phone. If there was missing information on a questionnaire, the directors were contacted to ensure complete information from all participating centres.
TABLE Workload and wait time to first appointment in dedicated pediatric multidisciplinary pain treatment facilities across Canada

\begin{tabular}{|c|c|}
\hline & $\begin{array}{l}\text { Median } \\
\text { (IQ Range) }\end{array}$ \\
\hline Number of days of operation/week & $1(1-2)$ \\
\hline Number of new consultations in last 12 months & $31(30-86)$ \\
\hline Number of follow up visits in last 12 months & $450(300-1120)$ \\
\hline Number of patients waiting & $10(2-17)$ \\
\hline *Wait time (weeks) & $4(2-6)$ \\
\hline
\end{tabular}

\section{Measurement tool}

The survey questionnaire used in this study was adapted from the Quebec Chronic Pain Clinic Survey. ${ }^{18}$ The questionnaire covered: 1) organizational structure of the MPTF; 2) clinical activities including volume of patients, wait lists, spectrum of chronic pain conditions treated, and treatment modalities offered or available within the institution; 3 ) staff composition and availability; 4) teaching and research activities; and 5) type of funding for services and overhead. The full questionnaire is available on the Journal website (www.cja-jca.org). Data were collected from June 2005 to August 2006.

\section{Data analysis}

Only those MPTFs that exclusively offered care to pediatric population were included in the analysis. The data from the questionnaires were coded, scored and entered into a Statistical Package for the Social Sciences (SPSS) database (SPSS Inc., version 11.0. Chicago, IL, USA). These data were analyzed to determine measures of central tendency and the distribution of values, and are presented as frequency, median and $25-75 \%$ interquartile ranges.

\section{Results}

\section{Distribution of MPTFs}

A total of 988 hospitals or rehabilitation centres were contacted. Only 321 of those healthcare facilities responded $(33 \%)$ and provided the contact information of 52 pain clinics in their facilities. Further search from compensation agencies (work or car accident), the Insurance Bureau of Canada, and pharmaceutical industry representatives yielded another 84 pain clinics. After screening those 136 clinics, only five met the MPTF definition and accepted pediatric patients exclusively. All eligible MPTFs returned the survey questionnaire for a response rate of $100 \%$. These 


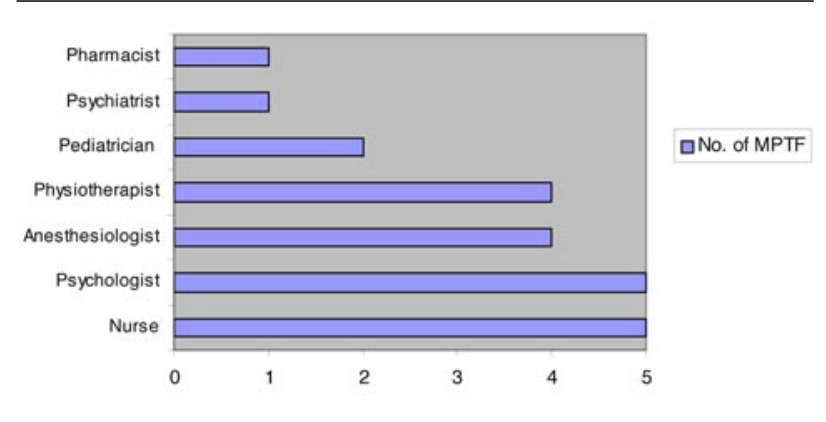

FIGURE 1 Healthcare professionals available and integrated in pediatric multidisciplinary pain treatment facilities.

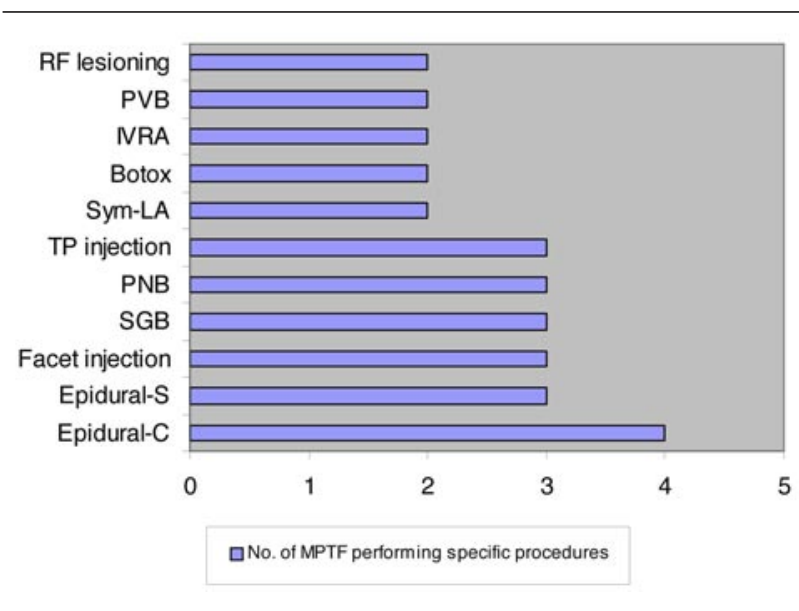

FIGURE 2 Types of interventional procedures offered in pediatric multidisciplinary pain treatment facilities. $\mathrm{RF}=$ radiofrequency; $\mathrm{PVB}=$ paravertebral nerve block; IVRA = intravenous regional anaesthesia; Sym-LA = sympathetic block with local anesthetic; $\mathrm{TP}=$ trigger point; $\mathrm{PNB}=$ peripheral nerve block; $S G B=$ stellate ganglion nerve block; Epidural-S = single epidural injection; Epidural- $\mathrm{C}=$ continuous epidural infusion.

clinics were located in five different provinces (Nova Scotia, Quebec, Ontario, Alberta, British Columbia), and had been in service for a median duration of eight years (interquartile range of 7-10 yr). One MPTF was established in 2006. Nineteen MPTFs accepted both adults and children but were excluded from the following analysis because the information obtained from these clinics reflected mainly pain management in adult populations.

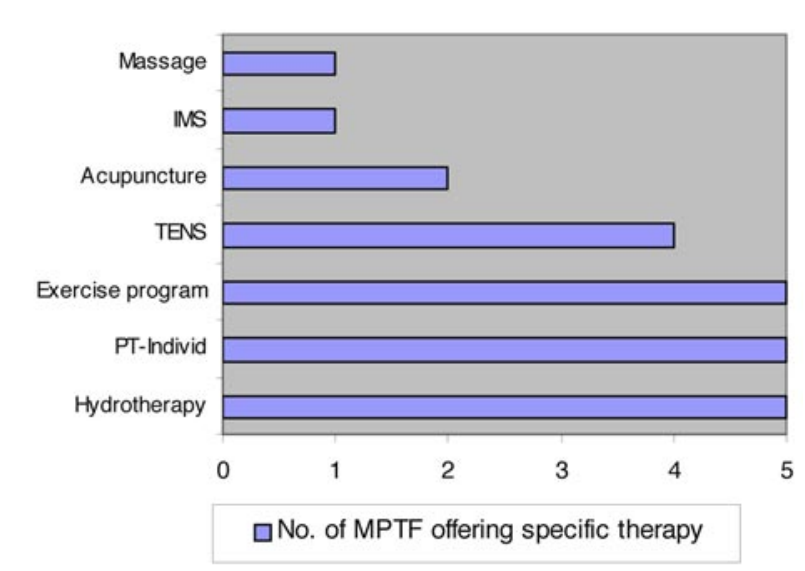

FIGURE 3 Types of physical therapy offered in pediatric multidisciplinary pain treatment facilities. IMS = intramuscular stimulation; PT - Individ $=$ individual physiotherapy; TENS $=$ transcutaneous electric nerve stimulation

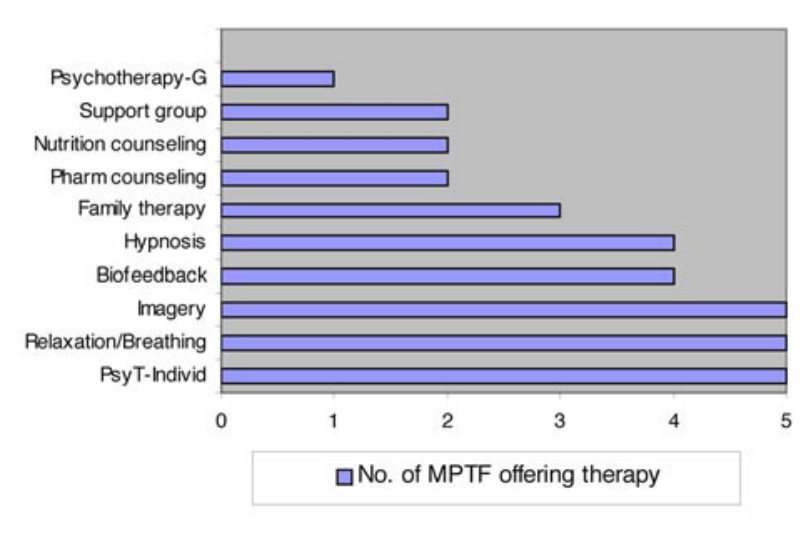

FIGURE 4 Psychological therapy and counselling offered in pediatric multidisciplinary pain treatment facilities. Psychotherapy-G = group psychotherapy; Psy T-Individ = individual psychotherapy.

\section{Characteristics and clinical activities of pediatric MPTFs}

Workload and wait times to obtain a first appointment are shown in the Table. Although the median wait time was four (two to six) weeks, the wait time in one MPTF was as long as nine months. Headache and neuropathic pain were rated as the most commonly treated pain syndrome in children (four out of five MPTFs), followed by abdominal pain (two out of 
five MPTFs). Multidisciplinary pain treatment facilities employed a wide variety of healthcare professionals as shown in Figure 1. Anesthesiologists, nurses, psychologists and physiotherapists were the most common health care providers involved in integrated pediatric MPTFs. Although not integrated in the MPTFs, a wide variety of medical specialties (e.g., neurologists, pediatric consultants) and other healthcare professionals (e.g., social workers) were also commonly available for particular cases as needed. All MPTFs held regular multidisciplinary meetings to review individual clinical cases. With the exception of one MPTF, all provided a variety of interventional procedures as shown in Figure 2. All MPTFs offered a wide range of physical and psychological therapies as shown in Figures 3 and 4.

\section{Teaching and research activities}

All MPTFs provided teaching and training for residents or students from various medical specialties and other healthcare professions. Anesthesiology and pediatrics were the medical specialties most commonly involved in the teaching programs. Nursing, psychology and physiotherapy also frequently provided training for their trainees as well. With the exception of one MPTF, all provided pain management specialty fellowship training (80\%). Three MPTFs engaged in research activities. Two employed full-time research staff and one had a research coordinator. Only one MPTF had designated research facilities. Four MPTFs regularly collected or audited the outcome data of their clinic.

\section{Discussion}

This survey provides a comprehensive national overview of the clinical activities and infrastructure of pediatric MPTFs in Canada. We found that only five MPTFs treat pediatric patients exclusively; all are located in major urban cities across the country. Although the average wait time for a first appointment was lower for pediatric patients (median of four weeks) than for adult chronic pain sufferers in Canada, ${ }^{17}$ the wait time in one MPTF was nine months while another MPTF included in this survey had been opened for only six months at the time of our data collection. A significant proportion of children with chronic pain that could benefit from these services do not have adequate access to these specialized clinics.

Although not every chronic pain patient requires a multidisciplinary approach, ${ }^{15}$ services provided by MPTFs are considered the optimal therapeutic paradigm for the management of chronic pain in children. ${ }^{9,10}$ This optimal paradigm of treatment is unavailable in rural areas in only half the provinces and none of the Territories. A lack of specialized pediatric MPTFs is a concern given that children with unexplained and explained chronic pain have been found to have substantial impairment in all aspects of everyday life. ${ }^{4-7}$ For example, children with unexplained pain are often caught up in a biomedical driven-model of health care, having been investigated extensively and evaluated by multiple physicians and specialists. When the symptoms remained unexplained (not organic in nature) the patient is usually referred to a mental health provider with a view that the pain is psychological in nature. The child may spiral into increasing pain-related disruption of function which has been labelled as "pain-associated disability syndrome". ${ }^{19}$ This results in not only reduced quality of life for the child and family but also dramatically increases health care utilization..$^{8,20}$ Thus, timely access to specialized pediatric MPTFs is integral to reducing health care costs and improving the health outcomes for Canadian children suffering from chronic pain.

Recent epidemiological data have shown that chronic pain is not a uniquely adult problem. ${ }^{16}$ According to international estimates, $15-25 \%$ of all children and adolescents suffer from recurrent or chronic pain. ${ }^{1,2,21}$ Girls report more pain than boys, and the incidence peaks at an average age of $14 \mathrm{yr}^{1,22}$ The most common complaint is headache (tension-type more common than migraine), ${ }^{23}$ followed by functional abdominal pain ${ }^{24}$ and musculoskeletal pain. ${ }^{25}$ Children tend to have pain in multiple sites. In adults, the top four pain syndromes treated in MPTFs are low back pain $(28 \%)$, neck pain $(22 \%)$, neuropathic pain $(11 \%)$, and headache (10\%). Differences in definitions, measurement of pain across studies in adults and children, cumulative risk of exposure to trauma, and age-related differences in disease pattern may account for these differences. However, there is some evidence that differences may relate more to developmental and psychosocial factors. $^{22,26}$ For example, Martin et al. ${ }^{22}$ examined the long-term pain and disability outcomes of a pediatric chronic pain clinic cohort and found that females with psychosocial risk factors (e.g., school or social withdrawal, anxiety and depression) contributing to their pain at the time of initial treatment were found to be at greater risk for continuing pain than males. In addition, children may use different and have a more limited repertoire of coping strategies to deal with pain compared to adults. ${ }^{27}$ Finally, little is known about the natural history, risk factors and impact of pain on the lives of children and their families.22 Further longitudinal case control or cohort studies are needed to identify the differential risk factors for chronic pain in children. 
All established dedicated pediatric MPTFs in Canada treat chronic pain in children from an interdisciplinary, multimodal, rehabilitation perspective. The current evidence suggests that a multimodal approach incorporating pharmacological, physical and psychological therapies into a flexible, child-friendly program have the best outcomes. ${ }^{28,29, \mathrm{G}}$ Furthermore, because of the complexity of chronic pain in children, no single discipline has the expertise to assess and manage it independently. Therefore, specialized interdisciplinary chronic pain teams are now considered the standard of care for children with complex chronic pain conditions. ${ }^{9}, 10$ While there is good evidence for this approach in adults, ${ }^{11-14}$ the evidence base for this approach in children remains limited. ${ }^{9,10}$ In a recent Cochrane systematic review of all randomized controlled trials of interdisciplinary psychological treatment approaches, Eccleston and colleagues $^{29}$ found very strong evidence for the effectiveness of psychological treatment in reducing the pain of chronic and recurrent headache, and promising evidence for recurrent abdominal pain. In another study, Eccleston et al. ${ }^{28}$ found that an interdisciplinary cognitive behavioural chronic pain residential program was effective in reducing pain, pain-related distress as well as disability in adolescents with chronic pain.

\section{Limitations}

Although we could not exclude the possibility that some eligible MPTFs were missed, the multiple steps that were used to try and determine all pediatric MPTFs in Canada was a strength of this study. More importantly, great care was taken to identify in each province a study representative who had an excellent knowledge of the pain treatment facilities in his/her province through his/her contacts with professional associations or provincial pain societies. These persons had a key role in identifying missing MPTFs on the list with which they were provided. Recognizing that the absolute numbers are small, we were able to obtain a $100 \%$ response rate from all dedicated pediatric MPTFs. A second limitation relates to the data collection method (self-administered questionnaire vs face-to-face interview). However, all precautions were taken to ensure appropriate comprehension and completeness of responses to the questions.

In conclusion, this survey has identified that five dedicated pediatric MPTFs provide multidisciplinary care in pain management in Canada. The accessibility

G American Pain Society. Pediatric chronic pain: A position statement from the American Pain Society. American Pain Society Bulletin (Jan/Feb) 2001: 10-2. ok as a reference? of the pediatric MPTFs is quite limited. This study provides valuable information for policy makers and healthcare professionals to explore the best ways to provide optimal delivery of care for children suffering from chronic pain.

\section{Acknowledgements}

We thank Chelsea Maddock and Diana Bereti for their assistance in collecting and analyzing the data, and all the research coordinators and associates for their tireless efforts in conducting the survey. We also sincerely thank those who took the necessary time to complete the surveys.

\section{References}

1 Perquin CW, Hazebroek-Kampschreur AA, Hunfeld $J A$, et al. Pain in children and adolescents: a common experience. Pain 2000; 87: 51-8.

2 van Dijk A, McGrath PA, Pickett W, VanDenKerkhof $E G$. Pain prevalence in nine- to 13-year-old school children. Pain Res Manag 2006; 11: 234-40.

3 McGrath PA. Chronic pain in children. In: Crombie I, Croft P, Linton S, LeResche L, Van Korff M (Eds). Epidemiology of Pain. Seattle: IASP Press; 1999: 81101.

4 Konijnenberg AY, Uiterwaal CS, Kimpen JL, van der Hoeven J, Buitelaar JK, de Graeff-Meeder ER. Children with unexplained chronic pain: substantial impairment in everyday life. Arch Dis Child 2005; 90: 680-6.

5 Roth-Isigkeit A, Thyen U, Stoven H, Schwarzenberger $J$, Schmucker P. Pain among children and adolescents: restrictions in daily living and triggering factors. Pediatrics 2005; 115: e152-62.

6 McGrath PJ, Finley GA. Chronic and Recurrent Pain in Children and Adolescents. Seattle: IASP Press; 1999: $1-4$.

7 Dablquist LM, Switkin MC. Chronic and recurrent pain. In: Schechter NL, Berde CB, Yaster M (Eds). Pain in Infants, Children and Adolescents. Philadelphia: Lippincott Williams \& Wilkins; 2003: 98-215.

8 Sleed M, Eccleston C, Beecham J, Knapp M, Jordan A. The economic impact of chronic pain in adolescence: methodological considerations and a preliminary costof-illness study. Pain 2005; 119: 183-90.

9 Berde CB, Solodiuk J. Multidisciplinary programs for management of acute and chronic pain in children. In: Schechter NL, Berde CB, Yaster M (Eds). Pain in Infants, Children and Adolescents. Philadelphia: Lippincott Williams \& Wilkins, 2003: 471-86.

10 Stinson JN. Complex chronic pain in children, interdisciplinary treatment. In: Schmidt RF, Willis WD (Eds). Encyclopedic Reference of Pain. Heidelberg: Springer- 
Verlag; 2006.

11 Patrick LE, Altmaier EM, Found EM. Long-term outcomes in multidisciplinary treatment of chronic low back pain: results of a 13-year follow-up. Spine 2004; 29: 850-5.

12 Thomsen AB, Sorensen J, Sjogren P, Eriksen J. Economic evaluation of multidisciplinary pain management in chronic pain patients: a qualitative systematic review. J Pain Symptom Manage 2001; 22: 688-98.

13 Becker N, Sjogren P, Olsen AK, Eriksen J. Therapeutic results in chronic, non-malignant pain in patients treated at a Danish multidisciplinary pain center compared with general practice. A randomized controlled clinical trial (Danish). Ugeskr Laeger 2001; 163: 3078-82.

14 Jensen MP, Turner JA, Romano JM. Changes in beliefs, catastrophizing, and coping are associated with improvement in multidisciplinary pain treatment. J Consult Clin Psychol 2001; 69: 655-62.

15 Haldorsen EM, Grasdal AL, Skouen JS, Risa AE, Kronbolm K, Ursin $H$. Is there a right treatment for a particular patient group? Comparison of ordinary treatment, light multidisciplinary treatment, and extensive multidisciplinary treatment for long-term sick-listed employees with musculoskeletal pain. Pain 2002; 95: 49-63.

16 Eccleston C, Malleson PN, Clinch J, Connell H, Sourbut C. Chronic pain in adolescents: evaluation of a programme of interdisciplinary cognitive behaviour therapy. Arch Dis Child 2003; 88: 881-5.

17 Peng P, Choiniere M, Dion D, et al. Challenges in accessing multidisciplinary pain treatment facilities in Canada. Can J Anesth 2007; 54: 985-91.

18 Veillette $\Upsilon$, Dion D, Altier N, Choiniere M. The treatment of chronic pain in Québec: a study of hospitalbased services offered within anesthesia departments. Can J Anesth 2005; 52: 600-6.

19 Bursch B, Walco GA, Zeltzer LK. Clinical assessment and management of chronic pain and pain-associated disability syndrome. J Dev Behav Pediatr 1998; 19: 45-53.

20 Perquin CW, Hunfeld JA, Hazebroek-Kampschreur AA, et al. Insights in the use of health care services in chronic benign pain in childhood and adolescence. Pain 2001; 94: 205-13.

21 Roth-Isigkeit A. On epidemiology of persistent and/or recurrent pain (German). Monatsschrift Kinderheilkunde 2006; 154: 741-54.

22 Martin AL, McGrath PA, Brown SC, Katz J. Children with chronic pain: impact of sex and age on long-term outcomes. Pain 2007; 128: 13-9.

23 Laurell K, Larsson B, Eeg-Olofsson O. Headache in schoolchildren: agreement between different sources of information. Cephalalgia 2003; 23: 420-8.
24 Di Lorenzo C, Colletti RB, Lehmann HP, et al. Chronic abdominal pain in children: a clinical report of the American Academy of Pediatrics and the North American Society for Pediatric Gastroenterology, Hepatology and Nutrition. J Pediatr Gastroenterol Nutr 2005; 40: 245-8.

25 Connelly $M$, Schanberg $L$. Latest developments in the assessment and management of chronic musculoskeletal pain syndromes in children. Curr Opin Rheumatol 2006; 18: 496-502.

26 Diepenmaat AC, van der Wal MF, de Vet HC, Hirasing $R A$. Neck/shoulder, low back, and arm pain in relation to computer use, physical activity, stress, and depression among Dutch adolescents. Pediatrics 2006; 117: 412-6.

27 Branson SM, Craig, KD. Children's spontaneous strategies for coping with pain: a review of the literature.

Can J Behav Sci 1998; 20: 402-12.

28 Eccleston C, Malleson PN, Clinch J, Connell H, Sourbut C. Chronic pain in adolescents: evaluation of a programme of interdisciplinary cognitive behaviour therapy. Arch Dis Child 2003; 88: 881-5.

29 Eccleston C, Morley S, Williams AC, Yorke L, Mastroyannopoulou K. Systematic review of randomized controlled trials of psychological therapy for chronic pain in children and adolescents, with a subset meta-analysis of pain relief. Pain 2002; 99: 157-65. 